woollens, arranged by the Australian Wool Board. The last two, together with the many scenic tours possible from the three centres, proved of great interest to visitors who had not previously seen the Australian way and place of life. Post-Symposium tours to north and south Queensland and to New Guinea are now in progress-the last-named being for men only and at the invitation of the Commonwealth Government and the New Guinea Administration.

The lectures mentioned above will be published through the Publications Committee of the International Union of Pure and Applied Chemistry by Butterworth's Scientific Publications, London.

R. J. W. LE Fìvre

\title{
WARREN SPRING LABORATORY
}

TN planning the Warren Spring Laboratory at Stevenage, the Council for Scientific and Industrial Research decided that it should be a versatile station free to carry out research which cannot be fitted into the programme of another research body, especially work involving pilot-scale investigations of any subject of national importance.

As a result, the Laboratory's research programme includes a number of important investigations in several different fields*.

In chemical engineering, for example, the work is concerned mainly with providing the chemical plant designer with basic information. Considerably moro knowledge is required to achieve greater precision in design work. The basic programme is confined to the study of mass transfer in gas-liquid systems, and these investigations will provide data for the precise design of large-scale equipment without the need for costly pilot-plant studies. For example, the investigation should enable more accurate prediction of the performance of gas-liquid contacting equipment to be made and thus facilitate the design of equipment such as distillation columns and gas absorption towers.

Much of the work of the Mineral Processing Division is undertaken for mining companies and other organizations, on repayment. Three main subjects of basic research are being studied: (a) grinding in the presence of additives such as surfaceactive agents ; $(b)$ the composition of surface minerals and the kinetics of bubble attachment to mineral surfaces ; $(c)$ the behaviour of mineral particles in a high-tension field and the modifications of this behaviour by various surface treatments. There have been indications during the year that automation may become important in mineral processing plants and an experimental programme is being considered.

In the Process Development Department, work has continued on the Fischer-Tropsch synthesis,

* Report of the Warren Spring Laboratory, 1959. Published for the Department of Scientific and Industrial Research. (London: H.M. Stationery Office, 1960.) 3s. net. which provides a method of obtaining liquid and gaseous fuels from carbon monoxide and hydrogen, which are produced by the complete gasification of low-grade high-ash coal. Basic research on catalysis has included work on the catalytic and other physicochemical aspects of fuel cell operation.

A small human sciences research team is being formed at the Laboratory, and tho Human Sciences Research Sub-committee, under the chairmanship of Mr. H. Briggs, labour adviser to Unilever, Ltd., is now considering the programmes of research in this increasingly important field.

Current research into air pollution concerns both methods of abatement and assessment of atmospherie pollution throughout Britain, with relation to the effects of clean air legislation. Estimates madc during the year have shown that, in general, smoke from the burning of industrial coal has ceased to be a serious problem although in some instances it creates a local nuisance. The Laboratory has cooperated with the Port of London Authority and owners of tugs in demonstrating methods of reducing smoke emission from ships in coastal waters.

Smoke from Diesel exhausts provides another research problem. While a well-maintained and correctly operated Diesel vehicle need never produce black smoke, the fact remains that large numbers of lorries frequently do. Methods of removing smoke from exhaust gases are being studied. A 10-ton Diesel lorry fitted for road tests with various proprietary devices is being used for this purpose.

The Laboratory has continued to collaborate with local authorities on the measurement of pollution, and this is providing "a wealth of background information against which future improvements can be assessed".

Methods of measuring low concentrations of oxides: of nitrogen (known to be emitted by practically all fuel-burning appliances) are being examined. These emissions may be significant factors in air pollution.

\section{U.K. ATOMIC ENERGY AUTHORITY}

$\mathrm{T}$ HE sixth annual report of the Atomic Energy Authority, the first to appear over Sir Roger Makin's signature and also the first to be submitted to the Minister for Science, covers the period April 1, 1959-March 31, 1960*. During that year, those major projects undertaken primarily to support the

* United Kingdom Atomic Energy Authority. Sixth Annual Report for the period 1st April, $1959-31$ st March, 1960 . Pp. vi $+72+4$ plates. (London: H.M. Stationery Office, 1960.) 5s. net. defence programme were completod, and all main plants constructed for that purpose were operating successfully. New capital projects approved during the year were on a relatively small scale. The Authority continued to devote a major effort in support of the civil power programme of the Central Electricity Generating Board and the South of Scotland Electricity Board. The report includes as an appendix the observations of the Ministor for Science, in con- 
sultation with the Authority, on the fifth report of the Select Committee on Estimates on the Authority's Industrial Group. These comments have now been transmitted to the Committee.

Generally, the Authority welcomes the report and has accepted and will implement most of its recom. mendations. On the remaining recommendations, it is commented that the Authority has reviewed its budgeting procedure and taken steps to ensure that the original factory and laboratory estimates are prepared on as broad a basis as possible and contain no more detail than is essential to ensure the buildup of a realistic total. The Authority agrees with the Committee's view of the importance of taking account of long-term effects, both in staff and further capital expenditure, of current proposals, and will include in any application for sanction of a capital project connected with the development of a new reactor system a rough forecast of expenditure which may be necessary in the foreseeable future as a consequence of the particular capital project for which sanction is requested. The Authority also accepts that the Treasury should be informed of the contingency margin allowed in project estimates for experimental facilities for which it is impossible to give precise detailed specifications at the outset, and the Treasury will also be informed at the next stage of estimating what margin has been retained as a working margin. The Authority also accepts the general intention of the recommendation that it should be standard practice to allow design officers sufficient time to go out to tender for all major components of large civil reactor and plant projects, and fully endorses the Committee's statement that "the future course of the nuclear power programme will be directly affected by the availability or otherwise of the fast reactor in the early 1970 's, which means that its value must be established by about 1966". The fast reactor is regarded as an integral part of the nuclear power programme and the Authority will press on with its development as rapidly as possible: it is already receiving, and will continue to receive, full technical support.

On the financial side it must be observed that the balance sheet appended to the report still gives no indication as to the way in which the $£ 92,433,010$ of the 1959-60 estimates were expended. The sixth report, like its predecessors, gives no indication whatever of the magnitude of our effort in research on nuclear energy or of the cost of the nuclear power programme, either as a whole or in the development of reactors. Indeed, even less information is available than was to be found in some earlier reports, though it is stated that early in $\mathbf{1 9 5 9}$ the Authority decided to limit the growth of man-power on research and development for the next three years to an annual rate of not more than 8 per cent. Within this rate of expansion, recruitment in general has been satis. factory, although difficulty is still experienced in recruiting engineers and scientists of sufficient experience and calibre for higher management posts, and in obtaining scientific and professional staff in particular disciplines in which there is a national shortage. 'The total staff employed increased from 35,260 on April 1, 1959, to 38,500 on March 31, 1960, industrial employees increasing from 18,217 to 19,572 .

On the production side the report records an increase of 40 per cent in the output of fissile material and of 300 per cent in that of electricity, while most of the teething troubles of the full-scale prototype unit for converting uranium nitrate into tetrafluoride, using fluidization techniques, have boen overcome, and the plant is operating as a production unit yielding uranium tetrafluoride of good quality at the design throughput. Satisfactory progress is also recorded in the reactor development programme, and stress is laid on the importance of reductions in capital costs if nuclear power is to be competitive not only at base load but also at the lower load factors at which nuclear power stations will have to operate when substantial nuclear capacity has been built. This largely depends on the development of more advanced reactors, and here a large effort has been devoted to the support of the 'magnox' stations, particularly the development of fuel elements to provide good performance with reliability. Progress in the advanced gas-cooled reactor system has been encouraging: the system should be capable of lower capital costs than 'magnox' stations and its prospects are good. Development of the fast reactor proceeded steadily, and the experimental reactor at Dounreay came into operation at, low power. Most of the staff working on the hightemperature gas-cooled reactor system were seconded to the Dragon project, under the auspices of the Organization for European Economic Co-operation. Other work on reactors included investigations into the design of a steam-cooled heavy-water reactor and its variant, the steam generating heavy-water reactor.

The wide range of the Authority's research activ ities is displayed in the chapter on general research and development. In nuclear physies, for example, a major group of work is concerned with the behaviour of nucleons when they collide in free space, uncomplicated by the proximity of other nucleons as in nucleon-nuclear reactions. The cyclotron has also been used to investigate the interaction of a highenergy nucleon with a nucleus and the interactions between nucleons and nuclei have also been studied at fairly low energies, using the 5-MV. Van do (traaff generator and newly completed 12-MV. tandem electrostatic accelerator at Harwell. A now particle detector has been developed in which a $p-n$ junction in a serniconductor, such as silicon or germanium, is used as a solid-state ion chamber to produce an electrical impulse when a nuclear particle traverses the junction. and also a large heavily shielded liquid scintillation counter for work on neutron emission in fission. In solid-state physics a fundamental experiment has: been carried out using lithium isotopes, and a change of thermal resistance with isotope concontrations was observed in measurements at Capenhurst of tho thermal conductivity of single crystals of lithium fluoride containing lithium- 6 and lithium -7 in the temperature range $10^{\circ}-90^{\circ} \mathrm{K}$. In radiation chemistry much work has been undertaken in connexion with the problems of radiation change in reactors and in fuel processing plants. For example, work on the $\gamma$-radiolysis of methyl acetate has shown how complicated the degradation of a simple ester can be, and work on the radiolysis of trialkyl phosphates showed that, in addition to hydrogen and light hydrocarbons. dialkyl and smaller amounts of mono-alkyl phosphoric acids are produced. The behaviour of the system carbon dioxide/carbon monoxide/graphite under irradiation has been studied to determine the basic parameters that affect the rates of the roactions, and the influence of geometrical factors on the radiation-induced reaction producing carbon mon- 
oxide is being studied in sealed tubes. Another investigation was concerned with the nature and properties of radioactive aerosols, and laboratory experiments have been made on the release of iodine in air and carbon dioxide at very low vapour concentrations. Considerable technical work has been undertaken into oriticality to back particular design studies as well as a more generalized study.

Work continued on the application of radioisotopes, especially in industry. The method of fluorescence spectroseopy, using radioactive sources, has been applied to measuring very thin surface coatings, and by tracer methods the rate of flow of liquid in closed channels can now be measured with an orror of less than one part in 200. Further work has been dono on the use of large sources of $\gamma$-radiation for sterilization and other purposes, and a pilot-scale plant for irradiating packages of materials with $\gamma$-rays has been built at Wantage. A mass spectrometer has been developed at Capenhurst for the analysis of the active species present in gas/solid chemical roactions, and basic studies have been made of the friction and wear behaviour of materials in reactor coolant environments at high temperatures. Considorable progress has been achieved at Aldermaston in the provision of short-duration radiographs of systems opaque to ordinary light and moving at high speed, and two types of mechanical very-high-speed cameras are manufactured at Aldermaston, one, the streak eamera recording along a length of film the size of a light source which is varying with time, the other, the framing camera, producing individual pictures at intervals on a strip of film. A third type takes a single picture with a time of exposure of $1 \times 10^{-7}$ sec., using a Kerr cell shutter.

In the work on controlled thermonuclear reactions, the stored energy supply and the stabilizing magnetic field supply of Zeta were both increased by about six times during the year, and exporimental elucida. tion of the physical phenomena in the Zeta and Sceptre plasmas continued successfully, while work also continued on some other plasma physies prob- lems, and considerable progress was made in solving the formidable technological problems associated with the production and control of currents in the range of $10^{8}$ amp., and in the development of methods of construction to withstand the severe conditions expected in experiments such as the Intermediate Current Stability Experiment. The Authority has reconsidered its earlier decision to move controlled thermonuclear research from Harwell to Winfrith, and has chosen instead a site at Culham, whore the laboratories to be erected will form a large autonomous unit within the Authority's Research Group. The Authority's commitments under its long-torm uranium contracts are now greater than its immediate requirements, and for some years, mainly due to the slowing down of the nuclear power programme, it will hold larger uranium stocks than it needs. A new Health and Safety Branch, independent of the Groups, was: established as from July 1, 1959, to adviso on the formulation of health and safety policy and clisseminate this policy for application by heads of groups and establishments, apply this poliey to the assessment and inspection of reactors and plant, and provide the focal point for condueting external relations in this field. A wide range of health and safety problems investigated during the year included developments in measuring techniques applied to the monitoring of fall-out from nuclear weapon tests, controlled studies of the uptake from fresh water of strontium-90 by fish and of this and other radioisotopes by common aquatic plants, and work on the diffusion and dispersion of gases and particulates.

Information Services have included, besides the Harwell Reactor School, the Calder Operation School, the Isotope School, now at Wantage, and the training programme for Central Electricity Generating Board oporating staff, the issue of an illustrated summary of this sixth annual report, together with some additional material to July $1,1960^{*}$.

*Atom 1960 : an Illustrated Summary of the Sixth Annual Report from 1st April, 1959, to 31st . Warch, 1960, of the United Kingdom Atomic Energy Authority, with some additional material to ist July, 1960. Pp. 34. (Tondon: H.M. Stationery Otfice, 1960.) 2s. 6d. net.

\section{TUBERCULOSIS: RISK TO FAMILY CONTACTS}

$I^{\mathrm{N}}$ developed countries with adequate hospital ccommodation, drug treatment of tuberculosis has often freed beds. In less-developed countries with inadequate hospital accommodation, the problem of beds for tuberculous patients remains acute. In India, for example, it is particularly serious, since there are only 23,000 beds for tuberculous patients, against a total number of persons affected that may be put at between 1.5 and 2.5 million. Because of this, a comparative study of domiciliary and sanatorium treatment of tuberculosis was undertaken by the Tuberculosis Chemotherapy Centre, Madras, which was set up in 1956 under the joint auspices of the World Health Organization, the Indian Council of Medical Rescarch, the Madras Government and the Medical Research Council of Great Britain. The purpose of the study was to determine whether drug treatment of tuberculosis in a country like India was as effective in the home as in the sanatorium; or, to put it differently, whether domiciliary treatment did away with the need to send a fair number of tuber- culosis patients to hospital (World Health Org. Chron., 14, No. 7 ; July 1960).

A group of 193 patients were selected, most of them from the poorest classes of Madras City. They had to be more than twelve years old, to have had no previous drug treatment, and to have a positive sputum. Out of these 193 patients, 96 were treated at home, 97 in the sanatorium. The period of comparison lasted a year, and the results of the study indicated that domiciliary treatment seemed to give as good results as sanatorium treatment.

There remains the important point whether the risk of infection to the family is not greater when the patient is treated at home. A fresh study was carried out under World Health Organization auspices on the same group of patients to determine the overall prevalence of cases of tuberculosis among family contacts when the diagnosis of tuberculosis was established in the family member included in the comparative study (the index case), and the number of fresh clinical and primary cases occurring among 